\title{
METHYLENE BLUE PHOTODYNAMIC THERAPY VERSUS TUBERCULIN PURIFIED PROTEIN DERIVATIVE (PPD) IMMUNOTHERAPY IN PLANE WARTS IN CHILDREN
}

\author{
By
Azmy Ahmed Abdul Latif, MD, Ibrahim Mohammad Abd El-Kareem, MD, Ayman Mohamed Abd El-Maksoud Hasan, M.B.B.Ch \\ Department of Dermatolgy, Venereology, and Andrology, Faculty of Medicine, Al-Azhar \\ University
}

Corresponding author: Ayman Mohamed Abdel maksoud Hasan,

Mobile: (+20) 01095943704, E-mail: ayman444486@gmail.com

\begin{abstract}
Background: Plane warts are caused by human papilloma virus (HPV) (most often HPV-2, HPV-3 or HPV-10) and generally multiple, slightly elevated, smooth papules occurring most often on the face, hands, neck, and legs of children and young adults.

Objective: To compare the efficacy and safety daylight photodynamic therapy using methylene blue versus tuberculin purified protein derivative (PPD) immunotherapy intradermal injection in plane warts in children.

Patients and methods: Forty patients (Children) complaining of plane warts were enrolled in this study. They were randomly selected from the attendants of out-patient clinic Dermatology and Venereology Department, Al Hussein University Hospital, Faculty of Medicine, Al-Azhar University from April 2019 to November 2019. Patients were divided randomly into two groups, to undergo either methylene blue day light photodynamic therapy (MB-DL PDT) or tuberculin PPD intradermally.

Results: Tuberculin PPD-treated group showed significantly higher rates of complete response compared with MB- DL- PDT-treated group, complete response (60\% versus 30\% respectively); partial response (10\% versus $30 \%$ ), and no response (30\% versus $40 \%$ ).

Conclusion: PPD intradermally and MB-DL PDT has significant advantages over other treatments. Most treatment modalities were painful, needing multiple visits (time and money consuming), and were directed to each individual wart. This study confirmed that immunotherapy tuberculin PPD and MB-DL-PDT can be used to treat cutaneous Plane warts in children.
\end{abstract}

Keywords: Plane warts, HPV, MB-DL PDT, PPD

\section{INTRODUCTION}

Multiple plane warts a contagious viral disease that might be a disturbing cosmetic problem. Patients often request treatment because of social stigma or discomfort. Ideally, the treatment should be simple with a low risk of adverse effects. Treatment failure, recurrence or relapse are common because the traditional therapeutic approaches are sometimes less successful in eradicating 
the total HPV infection especially the subclinical and latent infections (Moreira et al., 2012).

Photodynamic therapy (PDT) is a technique that utilizes reactive oxygen species produced by a non-toxic dye or photosensitizer molecule in the presence of low intensity visible light to kill mammalian or microbial cells (Fathy et al., 2017).

The advantages of PDT are numerous. It is safe and non-invasive. Photodynamic therapy is not free of adverse effects. The most common one is pain during illumination. With the use of portable light sources to optimize the procedure and facilitate outpatient treatment, the concept of ambulatory PDT has emerged. The most important methodological simplification the therapeutic use of daylight (See et al., 2016).

Daylight-PDT is a simplified treatment procedure that improves tolerability by altering two key aspects of conventional PDT. The absence of occlusion and the use of daylight instead of an artificial light source make the daylight-PDT a more simple procedure where patients need to spend less time in the clinic. In addition, pain intensity during daylight-PDT is significantly lower than with conventional PDT, probably due to continuous production and photoactivation of small amounts of protoporphyrin IX (Wiegell et al., 2014).

Methylene blue (MB) is a widely known histological dye that has been in use to stain living organisms for many years. It belongs to the phenothiazinium class of compounds. It is well known to be photo dynamically active. The characteristic color of $\mathrm{MB}$ is caused by the strong absorption band in the 550-700 $\mathrm{nm}$ regions. Methylene blue has shown in vivo activity against several types of tumors when locally injected and illuminated with red laser light (Fathy et al., 2017).

Immune mechanisms may explain the spontaneous resolution of warts. The immune response elicited by human papilloma virus (HPV) includes the production of specific antibodies and cellmediated immunity with activation of $\mathrm{T}$ helper-1 (Th-1) lymphocytes. T-helper-2 (Th-2) secreted interleukin. Interleukin-4 (IL-4) helps in antibody secretion, while Interleukin-12 (IL-12) is one of the proinflammatory cytokines characteristic of Th-1-based immune response (Shaheen et al., 2015).

Immunotherapeutic modalities like PPD were used for treatment of recalcitrant warts. PPD is an extract of Mycobacterium tuberculosis, used for testing exposure to tuberculin protein, either from a previous vaccination or from the environment (Eassa et al., 2011).

Immunotherapy has the advantage over traditional treatments in that it presumably enhances recognition of the virus by the immune system. This allows clearing of the treated wart, and frequently warts at distant anatomic sites. Acquisition of human papillomavirus-directed immunity may also prevent future clinical infection (Thappa and Chiramel, 2016).

The aim of this study was to compare the efficacy and safety daylight photodynamic therapy using methylene blue versus Tuberculin Purified Protein Derivative (PPD) immunotherapy intradermal in plane warts in children. 


\section{PATIENTS AND METHODS}

Forty patients (Children) complaining of plane warts were enrolled in this study. They were randomly selected from the attendants of out-patient clinics of Dermatology and Venereology Department, El Hussein University Hospital, Faculty of Medicine, Al-Azhar University. From April 2019 to November 2019. Patients were divided randomly into two equal groups.

- Group I: Patients were treated with daylight photodynamic therapy using methylene blue (MB-DL PDT).

-Group II: Patients were treated with tuberculin purified protein derivative (PPD) immunotherapy (intradermal).

Cases included in this study were subjected to the following:

Parents gave informed consent to participate in this work. Participants or their parents had complete explanation about the nature, risks and purpose of the study.

1. Complete history taking included: Personal history, Present history and Past history.

2. General examination.

3. Complete dermatological examination: To determine the type, number, size, sites of warts and the presence or absence of distant lesions. The diagnosis of warts was made by clinical examination and patients were advised not to use any other wart treatment during the study period. Proper written consent was obtained after counseling.

4. Each patient was photographed. Photos were taken before starting treatment and every 1 or 2 weeks according to the group for 6 sessions.

5. Follow up of the patient for 3 months to detect recurrence or appearance of new lesions.

\section{Preparation of Methylene blue:}

Methylene blue hydrogel concentration was $0.1 \%$ was prepared by laboratory of Alezaby pharmacy:

- Methylene blue $(0.1 \mathrm{~g}$.

- Carboxymethyl cellulose (2g).

- Phenoxyethanolamine $(0.5 \mathrm{~g})$.

- Potassium sorbate $(0.5 \mathrm{~g})$.

- Distilled water to (100g).

\section{Storage of Tuberculin PPD:}

Tuberculin PPD was available at Vacsera Company. Tuberculin PPD solutions can be adversely affected by exposure to light. So we stored it in dark except when doses being actually withdrawn from the vial. Store between 2 and $8^{\circ} \mathrm{C}$ also the product which has been exposed to freezing was not used, avail of tuberculin PPD which had been in use for more than one moth was discarded because oxidation and degradation may have reduced the potency.

\section{Post procedure care for all patients in both groups:}

1. Topical, systemic antibiotics and analgesic anti-inflammatory were prescribed to the patient (in needed cases) to guard against infection and relieve pain.

2. The patients were asked to return after one week to Group 1 and two weeks to Group 2 for assessment of healing, the 
need for another session and complications.

3. Photographs were taken before and after response with the same camera settings and illumination.

Patients were following up at least for three months after the last treatment as regards observation of recurrence or appearance of new lesions.

\section{Statistical analysis:}

Data were analyzed using Statistical package for Social Science (SPSS) version 24. Quantitative data were expressed as mean \pm standard deviation
(SD). Qualitative data were expressed as frequency and percentage.

\section{The following tests were done:}

- Independent-samples t-test of significance: was used when comparing between two means.

- Chi-square test: was used when comparing between non-parametric data.

- P-value < 0.05 was considered significant.

\section{RESULTS}

There was no statistical significant difference between studied groups as regard age, sex, site and sessions of complete improvement.

The mean age in MB-DL PDT group was $9.8 \pm 2.04$ years with minimum age of 6 years and maximum age of 13 years while the mean age in PPD group was 9.6 \pm 2.5 years with minimum age of 5 years and maximum age of 13 years.

Were 3 males $(15 \%)$ and 17 females $(85 \%)$ in MB-DL PDT group while there were 8 males $(40 \%)$ and 12 females $(60 \%)$ in PPD group.

There were 13 patients $(65 \%)$ affected in the face and 7 patients (35\%) affected in other sites in MB-DL PDT group also there were 13 patients (65\%) affected in the face and 7 patients (35\%) affected in other sites in PPD group.
There were 8 patients (40\%) showed no response, 6 patients $(30 \%)$ showed partial response and 6 patients $(30 \%)$ showed complete response in $\mathrm{MB}-\mathrm{DL}$ PDT group while there were 6 patients (30\%) showed no response, 2 patients $(10 \%)$ showed partial response and 12 patients $(60 \%)$ showed complete response in PPD group.

For complete improvement in MB-DL PDT group, 1 patient $(16.7 \%)$ required 3 session, 1 patient $(16.7 \%)$ required 4 sessions, 1 patient $(16.7 \%)$ required 5 sessions and 3 patient $(50 \%)$ required 6 sessions while for complete improvement in PPD group, 1 patient $(8.3 \%)$ required 3 session, 3 patients $(25 \%)$ required 4 sessions, 3 patients $(25 \%)$ required 5 sessions and 5 patients $(41.7 \%)$ required 6 sessions (Table 1).

Table (1): Comparison between studied groups as regard age, sex, site, response and sessions of improvement

\begin{tabular}{|l|c|c|}
\hline \multirow{2}{*}{ Age } & MB - DL PDT & PPD \\
\cline { 2 - 3 } & $\mathbf{N}=\mathbf{2 0}$ & $\mathbf{N}=\mathbf{2 0}$ \\
\hline Range & $6-13$ & $5-13$ \\
\hline
\end{tabular}


METHYLENE BLUE PHOTODYNAMIC THERAPY VERSUS...

\begin{tabular}{|c|c|c|c|c|}
\hline Mean \pm SD & \multicolumn{3}{|c|}{$9.80 \pm 2.04$} & $9.60 \pm 2.50$ \\
\hline P. value & \multicolumn{4}{|c|}{0.783} \\
\hline Sex & & MB - DL PDT & PPD & Total \\
\hline \multirow{2}{*}{ Male } & $\mathbf{N}$ & 3 & 8 & 11 \\
\hline & $\%$ & $15.0 \%$ & $40.0 \%$ & $27.5 \%$ \\
\hline \multirow{2}{*}{ Female } & $\mathbf{N}$ & 17 & 12 & 29 \\
\hline & $\%$ & $85.0 \%$ & $60.0 \%$ & $72.5 \%$ \\
\hline \multirow{2}{*}{ Total } & $\mathbf{N}$ & 20 & 20 & 40 \\
\hline & $\%$ & $100.0 \%$ & $100.0 \%$ & $100.0 \%$ \\
\hline P-value & \multicolumn{4}{|c|}{0.077} \\
\hline Site & & MB - DL PDT & PPD & Total \\
\hline \multirow{2}{*}{ Face } & $\mathbf{N}$ & 13 & 13 & 26 \\
\hline & $\%$ & $65.0 \%$ & $65.0 \%$ & $65.0 \%$ \\
\hline \multirow{2}{*}{ Other } & $\mathbf{N}$ & 7 & 7 & 14 \\
\hline & $\%$ & $35.0 \%$ & $35.0 \%$ & $35.0 \%$ \\
\hline \multirow{2}{*}{ Total } & $\mathbf{N}$ & 20 & 20 & 40 \\
\hline & $\%$ & $100.0 \%$ & $100.0 \%$ & $100.0 \%$ \\
\hline P-value & \multicolumn{4}{|c|}{1.0} \\
\hline Response & & MB - DL PDT & PPD & Total \\
\hline \multirow{2}{*}{ No } & $\mathbf{N}$ & 8 & 6 & 14 \\
\hline & $\%$ & $40.0 \%$ & $30.0 \%$ & $35.0 \%$ \\
\hline \multirow{2}{*}{ Partial } & $\mathbf{N}$ & 6 & 2 & 8 \\
\hline & $\%$ & $30.0 \%$ & $10.0 \%$ & $20.0 \%$ \\
\hline \multirow{2}{*}{ Complete } & $\mathbf{N}$ & 6 & 12 & 18 \\
\hline & $\%$ & $30.0 \%$ & $60.0 \%$ & $45.0 \%$ \\
\hline \multirow{2}{*}{ Total } & $\mathbf{N}$ & 20 & 20 & 40 \\
\hline & $\%$ & $100.0 \%$ & $100.0 \%$ & $100.0 \%$ \\
\hline P-value & \multicolumn{4}{|c|}{0.117} \\
\hline $\begin{array}{l}\text { Sess. of } \\
\text { Improvement }\end{array}$ & & MB - DL PDT & PPD & Total \\
\hline \multirow{2}{*}{3} & $\mathbf{N}$ & 1 & 1 & 2 \\
\hline & $\%$ & $16.7 \%$ & $8.3 \%$ & $11.1 \%$ \\
\hline \multirow{2}{*}{4} & $\mathbf{N}$ & 1 & 3 & 4 \\
\hline & $\%$ & $16.7 \%$ & $25.0 \%$ & $22.2 \%$ \\
\hline \multirow{2}{*}{5} & $\mathbf{N}$ & 1 & 3 & 4 \\
\hline & $\%$ & $16.7 \%$ & $25.0 \%$ & $22.2 \%$ \\
\hline \multirow{2}{*}{6} & $\mathbf{N}$ & 3 & 5 & 8 \\
\hline & $\%$ & $50.0 \%$ & $41.7 \%$ & $44.4 \%$ \\
\hline \multirow{2}{*}{ Total } & $\mathbf{N}$ & 6 & 12 & 18 \\
\hline & $\%$ & $100.0 \%$ & $100.0 \%$ & $100.0 \%$ \\
\hline P-value & \multicolumn{4}{|c|}{0.905} \\
\hline
\end{tabular}

There were no complications except for hypopigmentation which was occurred in 1 patient $(5 \%)$ in MB-DL PDT group and local pain which was occurred in 6 patients $(30 \%)$ in PPD groups (Table 2)

Table (2): Complications in MB-DL PDT and PPD groups

\begin{tabular}{|l|c|c|}
\hline \multicolumn{1}{|c|}{ MB - DL PDT $(\mathbf{n}=\mathbf{2 0})$} & $\mathbf{N}$ & $\mathbf{\%}$ \\
\hline Burning pain & $\mathbf{0}$ & $\mathbf{0 \%}$ \\
\hline Mild itching & $\mathbf{0}$ & $\mathbf{0 \%}$ \\
\hline Mild irritation & $\mathbf{0}$ & $\mathbf{0 \%}$ \\
\hline Hypopigmentation & $\mathbf{1}$ & $\mathbf{5 \%}$ \\
\hline Hyperpigmentation & $\mathbf{0}$ & $\mathbf{0 \%}$ \\
\hline PPD (n=20) & $\mathbf{N}$ & $\mathbf{\%}$ \\
\hline
\end{tabular}




\begin{tabular}{|l|c|c|}
\hline Systemic side effect & $\mathbf{0}$ & $\mathbf{0 \%}$ \\
\hline Local pain & $\mathbf{6}$ & $\mathbf{3 0 \%}$ \\
\hline Imm. Hypersesitivity & $\mathbf{0}$ & $\mathbf{0 \%}$ \\
\hline Abcess & $\mathbf{0}$ & $\mathbf{0 \%}$ \\
\hline
\end{tabular}
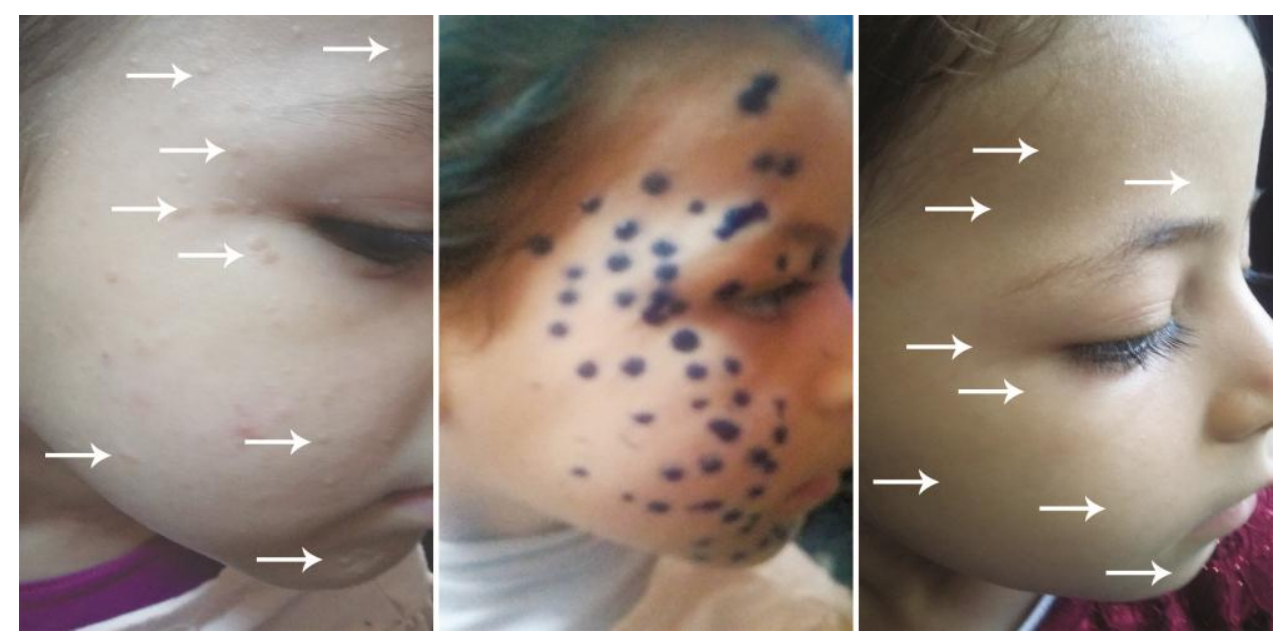

Photo (1): Female patient 6 y. with plane warts, complete improvement after four sessions of MB-DL PDT
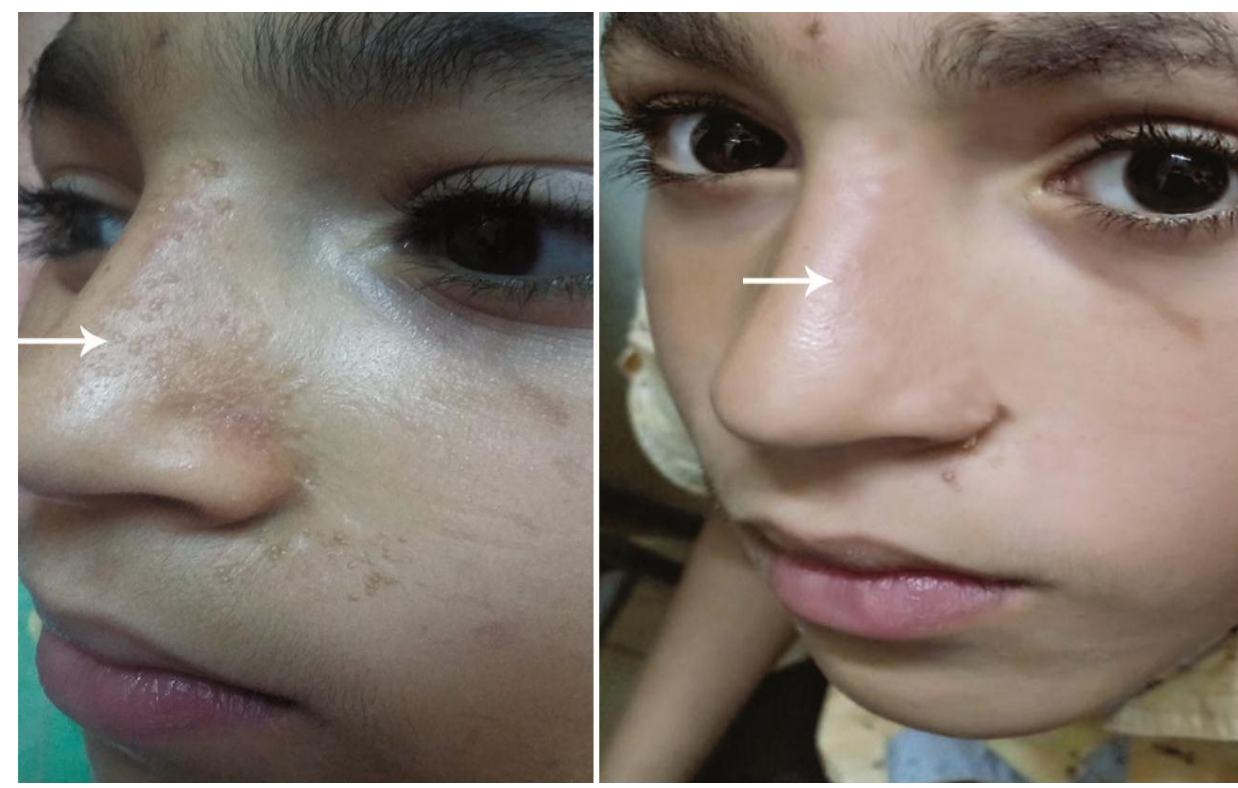

Photo (2): Male patient $13 \mathrm{y}$. with plane warts, complete improvement after five sessions of intradermal tuberculin PPD injection

\section{DISCUSSION}

The results of the present study revealed there were $40 \%$ showed no response, $30 \%$ showed partial response. This partial response mean decrease in size or number of plane warts only without clearance of wart, and $30 \%$ showed complete response in MB-DL PDT group.

Our results relatively matching with the results of using aminolevulinic acid as PDT in treatment of plane wart with plane 
wart (20\%), that results make the methylene blue has the priority in treatment of plane and common wart on aminolevulinic acid as it is more effective, cheap and more available (Yin et al., 2013).

Immune mechanisms have been suggested to explain the spontaneous resolution of warts. If this immunity could be enhanced, wart resolution could be long lasting. The stimulated immune system would destroy all warts in the body, saving the patients from local treatment for each individual wart (Mohamad et al., 2013).

It has been reported that untreated warts resolve after injection of immunotherapy that induces HPVdirected immunity. Antigens used for immunotherapy include tuberculin; BCG (Bacillus Calmette-Guérin); mumps, candida and trichophyton and MMR (vaccine against measles, mumps, and rubella) (Nofal \& Nofal, 2010 and Garg \& Baveja, 2014).

The exact mechanism of the clearance of warts with tuberculin PPD is not known. Its injection into the HPV infected Patient probably generates strong proinflammatory signals and attracts antigen presenting cells, which also recognize and process low profile HPV particles in the infected tissue. This leads to a strong adaptive immune response not only against mycobacterium tuberculosis but also against HPV. A similar mechanism has been proposed for the resolution of warts with skin test antigens such as mumps, candida and trichophyton antigens both at the injected as well as distant sites (Moubashera et al., 2016).
The mechanism of action of immunotherapy is still unclear. It may act through induction of strong nonspecific inflammatory response against the HPVinfected cells. It has also been suggested that the trauma itself may cause wart clearance in previously sensitized individuals (Mohamad et al., 2013).

Release of cytokines by immune system such as IL-2, IL-4, IL-5, IL-8, IFN- $\gamma$ and TNF- $\alpha$ stimulate a strong immune response against HPV may be another possible mechanism of action (Medrano et al., 2017).

The response to antigen injection was associated with proliferation of peripheral blood mononuclear cells that promotes Th1 cytokines, including interferon gamma and interleukin 2, which further activate cytotoxic $\mathrm{T}$ cells and natural killer cells that eradicate HPV-infected cells. The clearance of warts strongly indicates the development of a widespread HPVtargeted immunity as a response of antigen injection and represents a major advantage of the immunotherapy (Mohamad et al., 2013).

Our results with tuberculin PPDtreated group showed different response rate to those previously reported by the study which reported complete clearance in $93 \%$ of the target wart and $87 \%$ complete clearance of distant wart; (Palmoplantar and periungual warts) this may be explained as that study was based on intralesional injection (Palmoplantar and periungual warts) while in our study intralesional in children is so difficult and painful (Moubashera et al., 2016).

In the study that used tuberculin (PPD) as topical jelly in treatment of common warts $57 \%$ showed complete 
disappearance of their warts. The disappearance of warts usually occurred in the 3 rd or 4 th month. The strength of the tuberculin reactivity was not correlated with the disappearance of the warts. There were no side effects as pain and edema as seen with intralesional injection of PPD. The major disadvantage of topical tuberculin jelly was the long duration of treatment (Pundir et al., 2019).

Some studies used immunotherapy with different antigen injection; those antigens either single or multiple antigens. Single antigen using candida antigen with $85 \%$ clearance and slightly higher than $74 \%$ clearance, $72 \%$ clearance and with $51 \%$ clearance, Studies using single antigen either mumps or Candida antigens with $47 \%$ clearance. Other studies used combination of skin test antigens as mumps, candida and trichopyton with $70.9 \%$ clearance and with $53 \%$ clearance (Nofal and Nofal, 2010).

MMR vaccine was used in treatment of resistant warts either plantar warts as by Gamil et al. (2010) with $87 \%$ complete clearance, and common warts as by Nofal and Nofal (2010) with complete clearance in $80 \%$.

The relatively different response in the present study compared to the other related studies which utilize either a single antigen or a combination of antigens may be attributed to the differences in the number of the studied patients, the duration and the resistance of warts may also explain this difference. The difference may be attributed also to number of sessions.

Immunotherapy with tuberculin PPD is well tolerated. No serious side effects were reported in patients included in the present study. Only tolerable pain which was occurred in $30 \%$ during injection was the main side effect.

That responded to cold compression and topical corticosteroids Furthermore, none of our patients developed new lesions at the site of warts or at any distant site during the next 3 months following the procedure.

\section{CONCLUSION}

As regards the benefits to the patients, tuberculin PPD intradermal injection and MB-DL PDT has significant advantages over other treatments. Most treatment modalities are painful, needing multiple visits (time and money consuming), and are directed to each individual wart. The use of topical methylene blue and day light as a photodynamic therapy in the treatment of warts (plane warts) gave some results in plane warts. It was effective, cheap, available, and easy to use with minimal side effects. In immunotherapy treatments patients were able to resume normal daily activities and were free of residual scars which were very appreciated by all patients.

\section{REFERENCES}

1. Eassa BI, Abou-Bakr AA and ElKhalawany MA (2011): Intradermal injection of PPD as a novel approach of immunotherapy in anogenitalwarts in pregnant women. Dermatol Ther., 24: 13743.

2. Fathy G, Asaad MK and Rasheed HM (2017): Daylight photodynamic therapy with methylene blue in plane warts: a randomized double-blindplacebo-controlled study. Photodermatol Photoimmunol Photomed., 33 (4): 185-192. 
3. Gamil H, Elgharib I, Nofal A and AbdElaziz T (2010): Intralesional immunotherapy of plantar warts: report of a new antigen combination. J Am Acad Dermatol., 63:40-3.

4. Garg S and Baveja $S$ (2014): Intralesional immunotherapy for difficult to treat warts with Mycobacterium w vaccine. J Cutan Aesthet Surg.,7(4):203-8.

5. Medrano RFV, Hunger A, Mendonça SA, Barbuto JAM and Strauss BE (2017): Immunomodulatory and antitumor effects of type I interferons and their application in cancer therapy. Oncotarget, 8(41):7124971284 .

6. Mohamad NS, Badran $F$ and Yakout $E$ (2013): Evaluation of the efficacy of a combination-measles, mumps and rubella vaccine in the treatment of plantar warts. Our Dermatol Online, 4(4): 463-467.

7. Moreira LM, Lyon JP, Romani AP, Severino D, Rodrigues MR and Oliveira HP (2012): Phenotiazinium Dyes as Photosensitizers (PS). In: Photodynamic Therapy (PDT): Spectroscopic Properties and Photochemical Mechanisms, Advanced Aspects of Spectroscopy, MA Farrukh (Ed.), Intech, Open Access Publ., Ch.14: P.393422.

8. Moubashera AE, Hassana OM, Youssefa EMK and Sabekb MA (2016): Intralesional injection of purified protein derivatives versus zinc sulfate $2 \%$ in recalcitrant palmar and/or plantar warts. Journal of the Egyptian Women's Dermatologic Society, 13:151-158.

9. Nofal A and Nofal E (2010): Intralesional immunotherapy of common warts: successful treatment with mumps, measles and rubella vaccine. Journal of the European Academy of Dermatology and Venereology: JEADV, 24(10):1166-70.
10. Nofal A and Nofal E.: In tralesional immunotherapy of common warts: successful treatment with mumps, measles andrubella vaccine. J Eur Acad Dermatol Venereol, 24(10):1166-70.

11. Pundir M, Singh K and Kanodia S (2019): Efficacy of tuberculin purified protein derivative (PPD) immunotherapy in the treatment of plane warts on face. Official Journals By StatPerson Publication, 9:1.

12. See JA, Shumack S, Murrell DF, Rubel DM, Fernández-Peñas $\mathbf{P}$, Salmon $\mathbf{R}$, Hewitt D, Foley P and Spelman L (2016): Consensus recommendations on the use of daylight photodynamic therapy with methyl aminolevulinate cream for actinic keratosis in Australia. Australasian J Dermatol., 57:167174.

13. Shaheen MA, Salem SA, Fouad DA and El-Fatah AA (2015): Intralesional tuberculin (PPD) versus measles, mumps, rubella (MMR) vaccine in treatment of multiple warts: a comparative clinical and immunological study. Dermatol Ther., 28(4):194-200.

14. Thappa DM and Chiramel MJ (2016): Evolving role of immunotherapy in the treatment of refractory warts. Indian Dermatol Online J, 7(5):364-370.

15. Wiegell SR, Skødt V and Wulf HC (2014): Daylight-mediated photodynamic therapy of basal cell carcinomas- an explorative study. $\mathbf{J}$ Eur Acad Dermatol Venereol., 28(2):169175.

16. Yin R, Dai $T$, Avci $P$, Jorge AE, de Melo WC, Vecchio D, Huang YY, Gupta A and Hamblin MR (2013): Light based antiinfectives: ultraviolet $\mathrm{C}$ irradiation, photodynamic therapy, blue light, and beyond. Curr Opin Pharmacol., 13(5):731-62. 
مقارنة العلاج الضوئي النهاري مع الميتيلين الأزرق بالعلاج

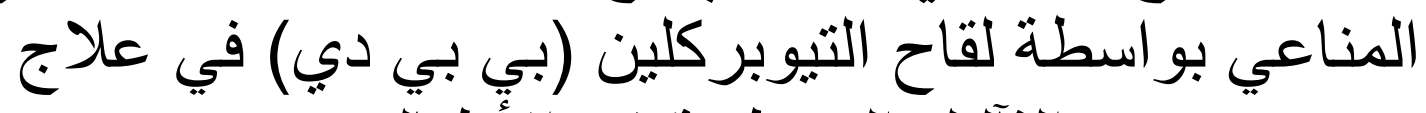
الثآليل المسطحة في الأُطفال

عزمى أحمد عبد اللطيف، إبراهيم محمد عبد الكريم، أيمن محمد عبد المقصود حسن قسم الجلاية والتناسلية، كليه الطب، جامعه الأزهر

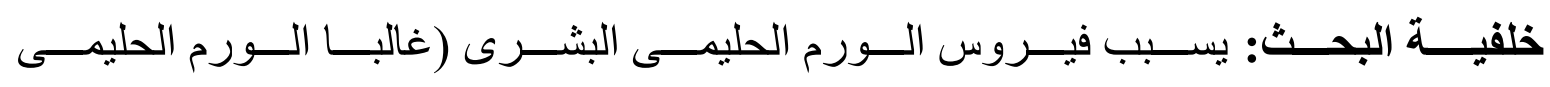

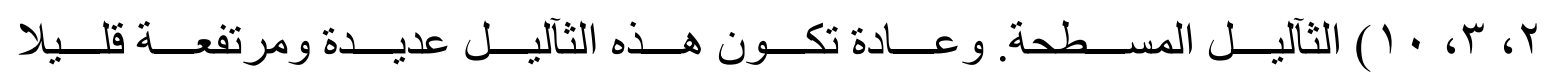

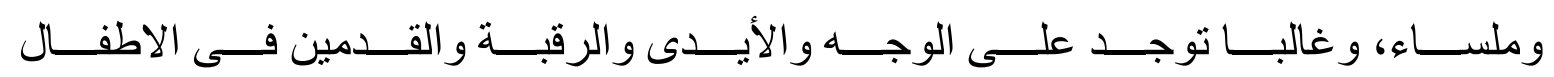

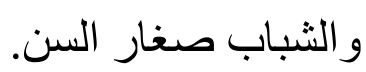

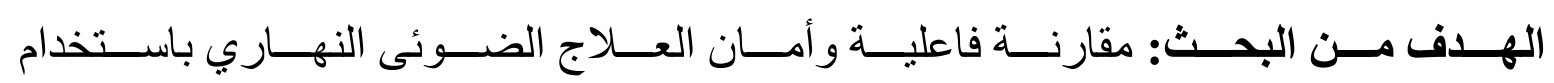

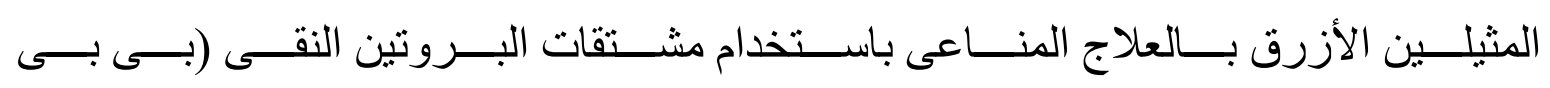
دى) فى علاج الثآليل المسطحة فى الاطفال

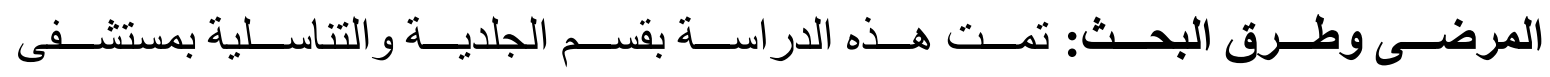

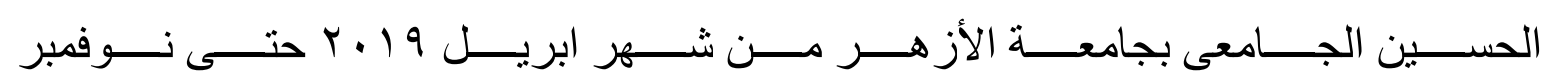

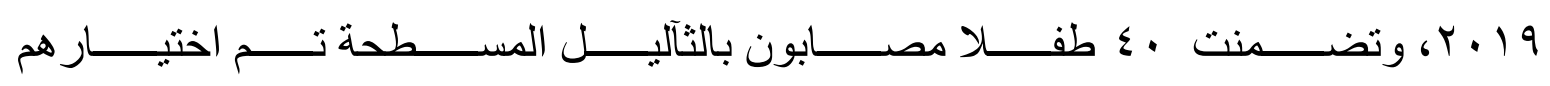

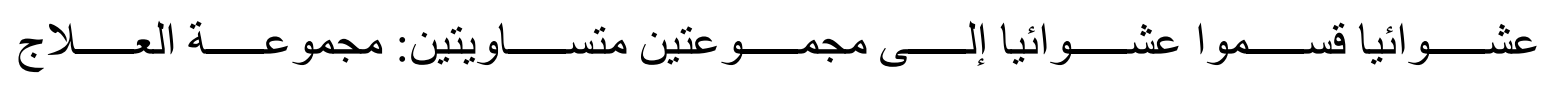

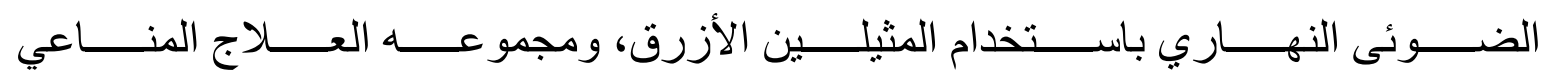
باستخدام مشتقات البروتين النقى (بى بى دى).

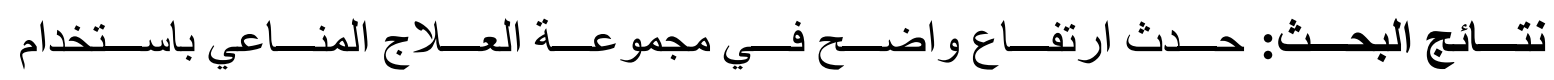

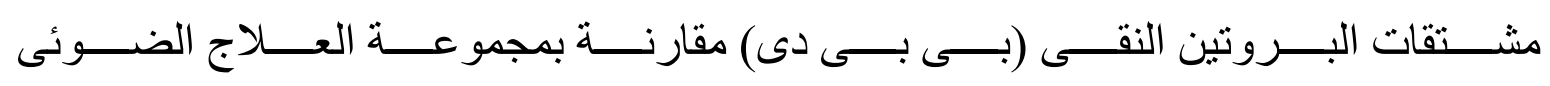

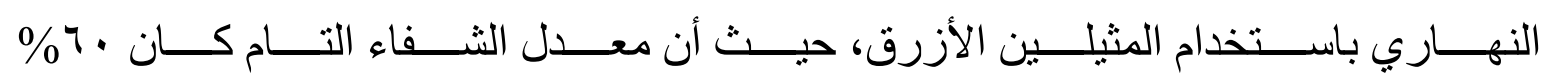

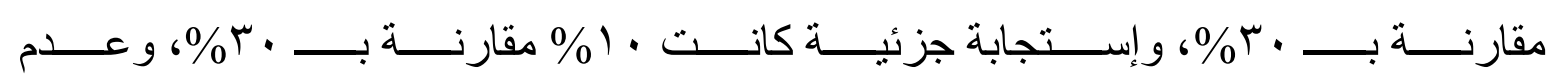

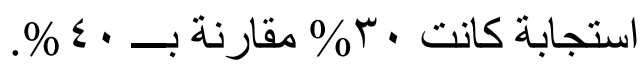




\section{METHYLENE BLUE PHOTODYNAMIC THERAPY VERSUS...}

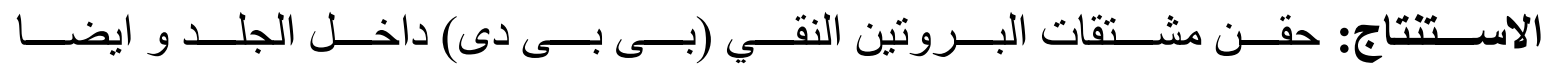

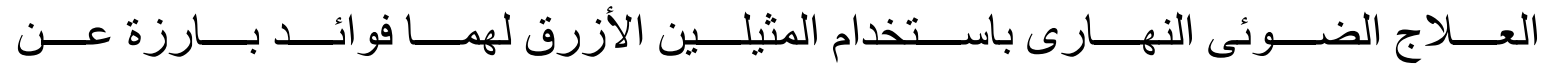
طـــرق العـــلاج الأخـــرى لأن غالبيـــة الطـــرق العلاجيـــة الأخـــرى مؤلمــــة وتحتــــاج

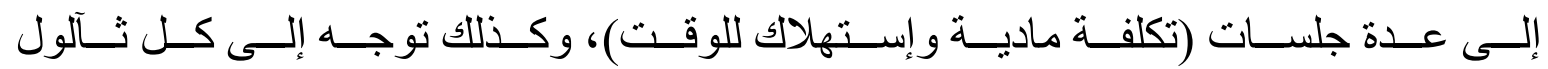

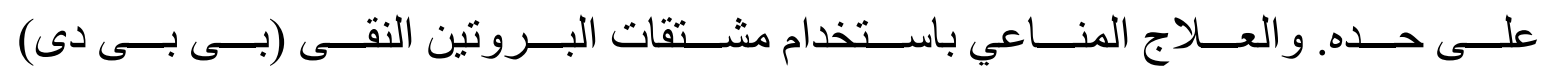

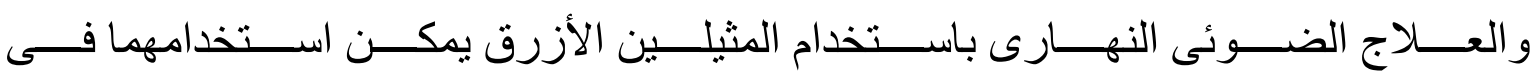
علاج الثآليل المسطحة فى الأطفال. 